Témoigner Témoigner. Entre histoire et mémoire

Getuigen Revue pluridisciplinaire de la Fondation Auschwitz

127 | 2018

Perpétuation de la violence après 1918

\title{
Uiteenlopende lotsbestemmingen: circusartiesten tijdens het nationaalsocialisme
}

Des destins divergents : les artistes de cirque sous le national-socialisme

\section{Annick Asso et Malte Gasche}

Traducteur : Rita Roggen

\section{(2) OpenEdition \\ Journals}

\section{Édition électronique}

URL : https://journals.openedition.org/temoigner/7836

DOI : $10.4000 /$ temoigner.7836

ISSN : 2506-6390

Cet article est une traduction de :

Des destins divergents : les artistes de cirque sous le national-socialisme - URL : https:// journals.openedition.org/temoigner/7828 [fr]

Éditeur :

Éditions du Centre d'études et de documentation Mémoire d'Auschwitz, Éditions Kimé

\section{Édition imprimée}

Date de publication : 1 octobre 2018

Pagination : 86-95

ISBN : 978-2-930953-076

ISSN : 2031-4183

Référence électronique

Annick Asso en Malte Gasche, «Uiteenlopende lotsbestemmingen: circusartiesten tijdens het nationaalsocialisme», Témoigner. Entre histoire et mémoire [Online], 127 | 2018, Online op 10 février 2022, geraadpleegd op 14 février 2022. URL: http://journals.openedition.org/temoigner/7836 ; DOI: https://doi.org/10.4000/temoigner.7836 
durende hongersnood in Warschau en uiteindelijk werd hij een clown. Waarom was hij populair? Dat kwam omdat mensen de behoefte hebben om te lachen. [...] De mensen waren niet bang voor hem, hij was populair en bracht hen aan het lachen. In een samenleving zonder kranten of radio was hij de figuur die iets weergaf van de samenleving. Iemand die lak heeft aan sociale normen, wordt als 'abnormaal' bestempeld en zo gezien was hij dus niet normaal. Zijn 'abnormaliteit' was echter een vorm van schranderheid. Hij wist hoe hij zijn tekstmoest voorbereiden, hoe hij het moest verwoorden en hoe hij verborgen boodschappen moest inbouwen. (Ostrower 2014, 366, vertaling RR).

Er bestaan verschillende versies over de dood van Rubinstein. In een ervan zou hij zijn terechtgesteld tijdens de avondklok. Hij zou erin zijn geslaagd om te roepen 'Ik val samen met Hitler'. In een andere versie overleed hij zoals hij leefde: hij zou zich vrijwillig hebben laten deporteren naar Treblinka, lachend en rennend rond de Umschlagplatz en hij zou op de trein zijn gestapt terwijl hij zijn nummertje lachend voortzette. (Engelking \& Leociak 2009, 594)

Yankele Hershokowitz maakte dan weer satirische liedjes die het leven in het getto beschreven en het onrecht dat de inwoners werd aangedaan door de bazen van de Judenrat. Hij gold als de troubadour van het getto. (Ostrower 2014, 369)

De nummerties van de clowns in de getto's beantwoordden an de traditie van

De Joodse hat zoals Ariela Krasney antoonde, mogelijk maakte dat de Joden een speciale vardigheid ontwikkelden om te lachen met onrecht, om het gemakkelijker te kunnen verdragen dankzij de humor.

CIRCUSVOORSTELLINGEN IN DE KAMPEN:

HET CIRCUS KONZENTRAZANIIN BORGERMOOR

In de werkkampen en de concentratiekampen vonden theater- en muziekvoorstellingen en minder vaak ook circusoptredens plaats, meestal op verzoek van de nai's nazis als vorm van vermaak. In sommige Stalags en Oflags nemen de gevangenen initiatief voor het spektakel.

In 1935 verschijnt in Keulen de getuigenis van de Duitse regisseur en acteur Wolfgang Langhoff (1901-1966): Die Moorsoldaten (De veensoldaten). Hij werd aangehouden in 1933 en door de Gestapo gefolterd. In juli van hetzelfde jaar vertrekt Langhoff naar het concentratiekamp Börgermoor in Emsland, een van de eerste concentratiekampen in wording. Langhoff maakt er meer bepaald melding van het circus Konzentrazani, een opvoering door hemzelf in augustus 1933 werd geregisseerd in het kamp. De naam 'Konzentrazani' is een directe allusie op het circus Sarrasani, opgericht in 1902 in Dresden en zeer populair in Duitsland. De Kommandantur had het spektakel toegelaten en de commandant en zijn mannen waren persoonlijk hoofdstuk de genese van het spektakel uit de doeken:
Ikvroeg in elke barak wie er een artistiek, humoristisch of ander talent had en ik was verrast over zoveel voorstellen. We vormden een veelzijdig gezelschap: acrobaten, turners, boksers, grappenmakers, zangers, imitatoren van dierengeluiden, jongleurs. (Langhoff 1935)

Het evenement volgde het typische schema van een circusspektakel: cabaret, scènes uit komedies, dieren gemaakt van lappen en touwtjes, muzikale intermezzo's om scènes kracht bij te zetten en de intrede van clown August voor te bereiden. Er liepzelfs een andereclown tusen het publiek om stukken turf te verdelen al iisjes warn ijsjes waren. Her moorlied, het lied van de veensoldaten, ultgegroeid tot symbool van de weerstand. De gevangenen van Börgermoor die naar de andere kampen werden overgebracht, namen het idee van het circus mee. Op die manier stond het model voor evenementen elders, ver weg van Börgermoor. In Neuengamme hebben de voormalige veensoldaten Heinrich Pakullis en Ernst Sawächter ook het circus doen heropleven met het idee dat je er steeds een beroep op moest doen 'in de loop van het leven, gedurende de doodsstrijd en na de dood' (Albrecht 1984, 183, vertaling RR)

\section{HET LOT VAN DE ARTIESTEN DIE NAAR AUSCHWITZ WERDEN GEDEPORTEERD}

Al deze optredens in de getto's en kampen gaven de gedeporteerden nieuwe moed en stimuleerden het verzet. De spektakels konden echter wel door de nazi's worden opgevist en uitgebuit, meer bepaald in de vernietigingskampen, waar de artiesten na hun ereronde werden gefolterd en/of uitgeroeid.

\section{Zoli Hirsch (1887-1944) en Lya Graf(1913-1941)}

twee dwergen vermoord in Auschwitz

Het verhaal van de beroemde Hongaarse clown en acrobaat Zoltán Hirsch, bekend onder de artiestennaam Zoli Hirsch, verdient zeker onze aandacht. Zoli Hirsch was een dwerg die shows en vaudevilles opvoerde In 1942 publiceert deze gerenommeerde artiest met wereldwijde fam zijn autobiografie onder de titel $K$ is gerenommeerde artie ember nagy élete [Het grote leven van een kleine artiest]. In 1943 vaardigden de Hongaarse autoriteiten een reeks antisemitische decreten uit. Enkele daarvan beperkten de tewerkstelling van Joden in artistieke beroepen. Hirsch werd als gevolg daarvan uit het Hongaarse circus Fényes gezet. Wanneer het Duitse leger in maart 1944 Hongarije veroverde, ging de situatie van de Joden van kwaad naar erger. Hirsch probeerde te overleven door met boeken te venten, maar werd daarvoor gearresteerd. Daarbovenop kwam nog het voorwendsel dat zijn ster te geel en te klein was, al stond ze helemaal in verhouding tot zijn gestalte. Hij werd gevangengenomen en meteen naar het concentratiekamp van Auschwitz-Birkenau gebracht. Daar werd Uirsch portier, gekleed in de meest onmogelijke uniformen, en onderging hij dagelijks vernederingen bij het lijks vernederingen bij in 1944. In de jaren zeventig werd deze grote kunstenaar onsterfelijk door de Roli

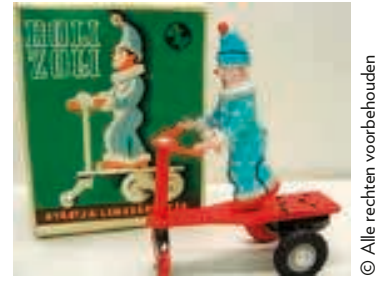




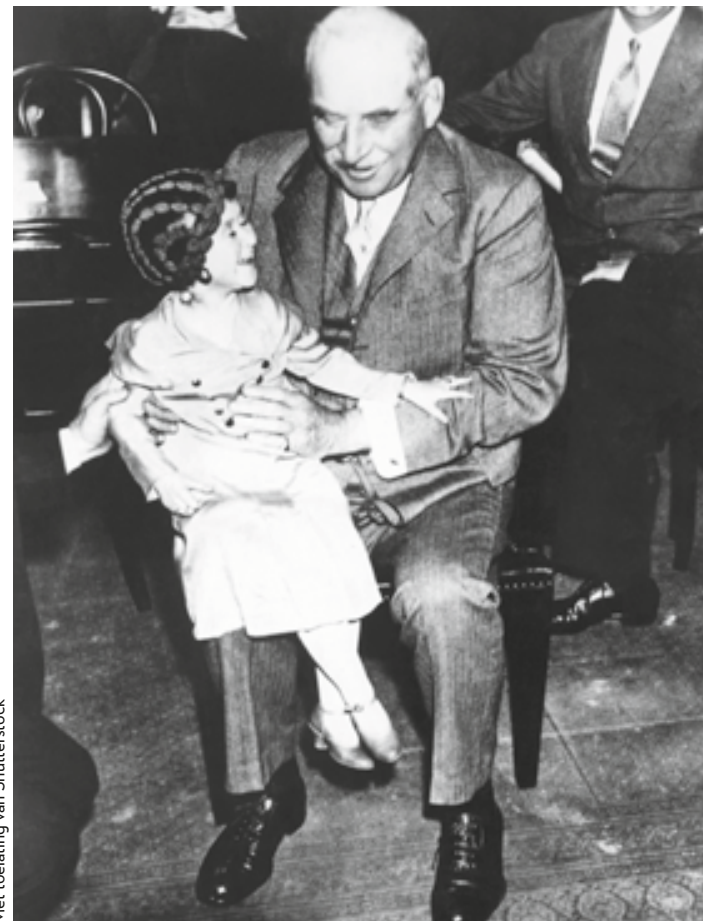

Zoli, een mechanisch speelgoedje van een blikken clown op een rode motorfiets.

Een gelijkaardig lot was ook Lya Graf (echte naam Li Schwartz) beschoren. Deze artieste was een Duitse, halfJoodse dwerg die werkte voor het beroemde Amerikaanse circus Ringling and Barnum \& Bailey. Ze werd beroemd in juni 1933, wanneer ze op de knie klom van Wall Street-bankier John Pierpont Morgan jr. J.P. Morgan genamd, die toen toen als derijktent( rond. Graf werd in 1937 gearresteerd door de Gestapo en overgebracht naar het concentratiekamp Sachsenhausen in de buurt van Berlijn. In 1941 werd ze gedeporteerd naar Auschwitz, waar ze omkwam in de gaskamer.

Defamilie Ovitz, onderzoeksobjecten

\section{van dokter Mengele}

In mei 1944 werden de zeven broers en zussen Ovitz, rondreizende Roemeense Joodse circusartiesten, naar Auschwitz gedeporteerd. Ze ontsnapten op het nippertje aan de gaskamer 'dankzij' de tussenkomst van dokter Josef Mengele. Deze laatste was gefascineerd door de kans om een volledige dwergenfamilie in zijn macht te hebben en zijn proeven op de dwerggroei tot een goed einde te
- Lya Graf op de schoot
van zakenman J.P. Morgan, 1 juni 1933. brengen. Zo zou hij bewijzen dat de Joodse afstamming leidde tot genetische anomalieën. De arts voerde op hen gruwelijke proeven uit, zoals ruggenmergpuncties en kokende waterdruppels in de oren gieten. Perla Ovitz (1921-2001), ten prooi aan een vorm van het syndroom van Stockholm, getuigde ten gunste van dokter Mengele in de documentaire Liebe Perla (1999) die haar werd gewijd. Dankzij hem kon ze immers ontsnappen an de dood, al waren de voorwarden afschuwelijk. Fani ze inm Fénelon, tegenover de dwergartiesten in haar getuigenis Sursis pour l'orchestre (Muziek achte prikkeldraad). De volgende passage geeft de intrede van een groep lilliputters weer die in heel Europa bekend is ${ }^{4}$, onder het bevel van dokter Mengele. Die had hen voo de gelegenheid in kostuums gestopt die werden geleend van de gedeporteerden, prachtige stoffen en schitterende juwelen, die een huiveringwekkende en bonte sfeer creërden:

Na het défilé op de piste maken ze sprongen, doen wat acrobatenkunstjes en stoten daarbij klappen uit. Het is nogal schrijnend. Wij spelen, De SS'ers lachen, mijn taak belet me niet om het merkwaardige spektakel gade te slaan. [...] De juwelen en de zijde fonkelen in de om het merkwaardige spektakel gade te slaan. [...] De juwelen en de zijde fonkelen in de
zon, ontsteken duizend bewegende, wervelende, walsende lichtpuntjes. Die schepsels sto- ten kleine vrolijke kreetjes uit, proberen te zingen met Clara, Lotte of mij. Ze hebben een schreeuwerige stem en krijsen. Het orkest zet een mars in, zij begeleiden door met handen en voeten te stampen. Ze hebben iets irreëels, schrikwekkends. Ben ik aan het ijlen? Neen, ik leef, ik hoor, ik zie.

Een publiek van gestreepte spoken metholleogen, enkel bezis met de eigen dood kijhto in in een hoeke no didente nietmeerwathspeling meebegannis. waarin misvormde wezens rondtollen, waar kinderhanden van soms vijftig jaar oud klappen. De SS'ers lachen. Die lach, onze muziek, die dwergen en hun maskerade worden een zodanig weerzin-

wekkend spektakel dat de meisjes beven van angst. Het is een enorme, dwaze lach die ons geschetter overstemt.

Schluss! roept Mengele en alles valt stil. Een arm zakt weer, een lach wordt een grimas. De opgeklopte vreugde verdwijnt van de gezichten en maakt plaats voor angst. Heeft hun meester hen iets te verwijten? Neen, de meester heeft voldoende gelachen, voldoende genoten van de anderen. Het feest is afgelopen [...] (Fénelon 1976, 319-322, vertaling RR).

Het zijn die tegenstrijdige individuele lotgevallen die ook talrijke geschriften en fictie hebben geïnspireerd, zoals de film De blikken trommel uit 1979, die een bijzonder licht werpen op de geschiedenis van het circus tijdens het nazisme.

Sioma Zubicky (1926-2014), overlevende van Auschwitz

Sioma Zubicky was van mening dat het zijn verantwoordelijkheid was om over de Shoah te vertellen an de jonge generaties. Daarom heeft hij zijn ervaringen in een autobiografisch verh (a) Europese landen. uropese landen.

Sioma Zubicky stamde uit een familie van Russische Joden en zag het leven in het Duitse circus Busch. Vader Boris was acrobaat en kunstruiter, maar de zoon had het uitzonderlijke talent om verschillende muziekinstrumenten te kunnen spelen. De voorliefde van Zubicky ging uit naar de xylofoon. Nadat hij verschillende jaren in het circus en in variétés in heel Duitsland, Tsjechoslowakije en Zwitserland had opgetreden, verhuisde Zubicky met zijn familie naar Parijs, waar ze in juni 1940 werden ingehaald door de Duitse bezetting. Ze doken niet onder. Zubicky en zijn vader gaven de voorkeur aan een andere strategie. Ze waagden zich in het hol van de leeuw en begonnen de troepen van de bezetter te verman. Omwille van han de leeuw en begon contacten methet 
Annie de Joodse wortels van de familie. Vader Boris slaagde erin te ontsnappen, maar Zubicky, 17, zijn broer Viktor, 11, en hun moeder Annie werden vanuit het kamp Drancy naar Auschwitz gedeporteerd. Zubicky kreeg het nummer 146.021, zijn broer en zijn moeder werden meteen vergast. Na zijn vrijlating in de buurt van Dachau keerde Zubicky in de lente van 1945 terug naar Parijs. In 1947 begeleidde hij Edith Piaf op haar tournee door Zweden.

\section{BESLUIT}

Zo brengt het circus voor enkele ogenblikken een beetje menselijkheid naar het getto en het kamp. Het neemt een belangrijke sociale dimensie aan en wordt zelfs een instrument van verzet en overleving voor sommige gedeporteerden. De optredens van de artiesten gaan van een solonummertje, bedoeld om landgenoten in de getto's en kampen moed in te geven, tot en met grotere producties, zoals die van het circus Konzentrazani dat met de beschikbare middelen talrijke elementen van het circus en het theater samenvoegt tot een totaalspektakel.

De circusnummers konden worden gerecupereerd dankzij het cynisme van de nazi's, die er een ziekelijk plezier in vonden om hun clowns in het spektakel te laten defileren vooraleer ze werden opgesloten in de laboratoria voor experimenten den marteling de vermaak schuilt de gruwel.

Vertaling uit het Frans: Rita Roggen

BIBLIO- EN FILMOGRAFIE

Betty M. Adelson, The Lives of Dwarfs. Their Journey from Public Curiosity toward Social Liberation, New Brunswick: Rutgers

Richard Albrecht, "Zirkus Konzentrazan" : eine Modellanalyse', Osterreichische Zeitschrift für Sociologie 9, 183-190.

- Ron Chernow, The House of Morgan: An Modern Finance, New York: Grove Press 1990.

Barbara Engelking \& Jacek Leociak, The Warsaw Ghetto, Yale University Press, 2009 Fania Fénelon, Sursis pour lorchestre, Parts Stock. 1976 .
- Raymond Gurême \& Isabelle Ligner, Interdit aux nomades, Parijs: Calmann-Lévy, 2011. - Zoltán Hirsch, Kis ember nagy élete (The
Great Life of a Small Man), Budapest: Great Life of a Small

- Anna Kérchy, 'From Showbiz To The Concentration Camp: The Fabulous, Freakish Life Of Hungarian Jewish
"Dwarf "Performers, Zoli Hirsch And The Ovitz Family', in Anna Kérchy \& Andrea Zittlau (red.), Exploring the cultural History
of Continental European Freak Shows and
Enfreakment, Cambridge, 2012, 211-232.

Yehuda Koren \& Eliat Negev, In Our Hearts
We Were Giants. The remarkable Story of the Lilliput Troupe - A Dwarf Family's Surviva of the Holocaust, New York: Caroll \& Grat
- Ariela Krasney, The Bachdan, Ramat Gan: Bar-llan University, 1999 Jewgeni Kusnezow, Der Zirkus der Welt, Wolfgang Langhoff, Die Moorsoldaten -Anna Lipphardt, 'Spielraum des Globalen: Deutschland und der Zirkus', in Ilfried Reichardt (red.).) Die Vermessung der Perspektiven, Universitätsverlag Winter
GmbH Heidelberg, 2008, 168-171. Chaya Ostrower, It kept us alive, Jeruzalem Yad Vashem, 2014

- Ingeborg Prior, Der Clown und die Zikkusreiterin, München: Malik, 1997. end de acrobate, vertalld uith het Duits door
Jan Smit, Baarn: De Kern Fontein, 2002 . - Shahar Rozen, Liebe Perla, documentair - Hans Scheugl, Show Freaks und Monster, - Volker Schlöndorff, Die Blechtrommel, film,
Frankriji/Duitsland/Polen, 1979, 163 min.

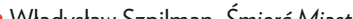
- Wiadystaw Szpilman, Smierć Miasta,
Warschau, 1946. Uitgebracht in het Engels
als The Pianist: The Extraordininary Story of ane Man's Survival in Warssaw, 1939-45. vertaald uit het Pools door Anthea $B$
Londen: Victor Gollancz Ltd 1999.

- Sioma Zubicky Spiel Zirkuskind ssoma Zubicky, Spiel, Zirkuskind,
spiel. EErinnerungen eines europaischen
Wunderkindes, Leipzig: Altberliner Verlaa
SITUATIE VAN DE CIRCUSSEN IN DUITSLAND ENFRANKRIJK GEDURENDE DE NAZIPERIODE

Gedurende de naziperiode wordt de circuswereld getroffen door een reeks beslissingen. Vanaf de maand mei 1933 is de tewerkstelling van elke buitenlander onderworpen aan een officiële werkverguning Bovendien zorgt verstrengingvandeze rstrenging van deze wetgeving 1934 ver antal werknemers in alle grote Duitse circussen. Op 14 februari 1935 legt een neuwe bepaling an alleciras de erplichting op om het bewijs van hun 'Arische' origine te leveren. Vanaf 1935-1936 ontsnapt dus ook het circus niet aan de arisering van de kunstensector, die duidelijk wordt wanneer artiestennamen niet meer vreemd mogen klinken, kostuums worden verboden, zwarte mensen of mensen van gemengde origine worden gebannen of Joden niet meer mogen deelnemen aan 'Duitse culturele' voorstellingen. Ook fysiek gehandicapten mogen niet meer optreden, matrich (1) ' kunnen ze de rol pelen van mythische personages of van figuren uit Germaanse legendes. Parallel daarmee genieten de grote Duitse circussen, zoals Sarrasani, Krone of Hagenbeck, van belastingvermindering en krijgen ze toelating om op tournee te gaan.

De circussen voeren duidelijk hun productie op in nazi-Duitsland gedurende de Tweede Wereldoorlog. In 1941 zijn er niet minder dan dertig miljoen toeschouwers in de twintig meest bezochte circussen in Duitsland. De ontspanning van een circusbezoek is inderdaad een van de meest gebruikte afleidingen om de bevolking gedurende de oorlog te sussen. Bovendien vormen de patriotische shows een volwaardig onderdel van de propaganda.

De administratieve maatregelen voor de circusmensen van de jaren dertig zijn geen privilege van nazi-Duitsland. Hetzelfde zien we gebeuren in Frankrijk, waar kleine familiecircussen een eeuwenoude traditie zijn en integraal deel uitmaken van het culturele leven op het platteland. Toch neemt de Franse regering de beslissing om het vrije verkeer van zogenaamde nomaden te beperken. Nog vóór Frankrijk werd bezet door de troepen van de Wehrmachtbeveelt een decreet van de minister van Binnenlandse zaken de opsluiting van alle groepen van nomaden in het kamp van Rivesaltes. 


\section{Irène Bento, gered dankzij het circus Althoff}

Irène Bento is een Duits-Joodse artieste die de Shoah heeft overleefd door van 1943 tot 1945 onder te duiken in het Duitse circus Althoff. Op verzoek van haa echtgenoot Peter Bento, een clown tewerkgesteld door het circus Althoff, aanvaard de jonge directeur Adolf Althoff Irène, haar zoon Peter jr, haar zus Gerda en haa moeder Alice. Inène makt vanaf dan deel uit van het trio van de clowns Bento en moeder

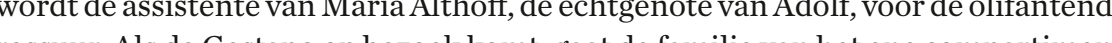
ressuur. Als de Gestapo op bezoek komt, gaat de familie van het ene compartimen van de circuswagen nar het andere. vaardige onder de Naties toegekend aan Adolf en Maria Althoff, die het leven van de familie Bento hebben gered.

Het leven van Irène Bento, meisjesnaam Irène Danner, werd door het Duitse collectief Projektgruppe im Nationalsozialismus in de vorm van een lecture as perfor-

$\diamond$ Roxana Küwen aan performance over de geschiedenis van de Duits-Joodse artieste
Irène Bento door het collectief Projektgrupp im Nationalsozialismus. Internationale Museumdas

n Berlijn, 21 mei 2017. mance op het toneel gebracht in het Statsmuseum Berlin - Museum Europäische Kulturen op de Internationale Museumdag van 21 mei 2017. Tijdens deze voorstelling werden passages uit het boek van Ingeborg Prior, Der Clown und die Zirkusreiterin (De clown en de acrobate) uit 1997 gelezen en visueel voorgesteld in de vorm van ime en trapeze.

te voorstelling is een mooi bewijs van de mogelijkheden van de spektakelkunst om de herinnering voort te zetten wanneer de directe getuigen van de Shoah verdwijnen. Getuigenissen als die van Irène Bento zijn bijzonder educatief als ze op die manier worden opgevoerd.

De interactieve website www.divergingfates.eu werd opgestart in het kader van het interdisciplinaire en intermatiole onderzoksprogrammad ina dat 2017 dor Malte Gasche werd opgestart, en loopt tot in 2019. De site bevat levensverhalen, beelden en uitgezochte documenten, lijsten uit archieven, een bibliografie en een enquête. Het doel van het onderzoeksprogramma is om eer te betuigen aan de vergeten artiesten van de geschiedenis van de Shoah door het leven, de

strategieën van de circusmensen Identité et Mémoire des gens de in Europa onder het juk van de nazi's te documenteren Zo wor deze weinig bestudeerde geschie-

Na een eerste workshop Ner de titel Travelling Circus People in Travelling Circus People in Europe during National-Socialism' op 29 en 30 mei 2017 in het Mémorial de la Shoah en aan het EHESS werd een tweede internationaal colloquium georganiseerd over de them tiek 'Forgotten Cosmopo cirques itinérants en Europe' Dat vond plaats in Montpellier op 5 en 6 april 2018, onder leiding van $\mathrm{dr}$. Malte Gasche, prof Philippe Goudard, dr. Annick Ahilippe Goudard, dr. Annick A internationale pour a mémoire de l'Holocauste, ondation pour la Mémoire de la Shoah, Fondation Kone (Finand) en de onderzoekscentra Centre for Nordic Studies, Helsiteit Paul Valéry-Montpellier 3.

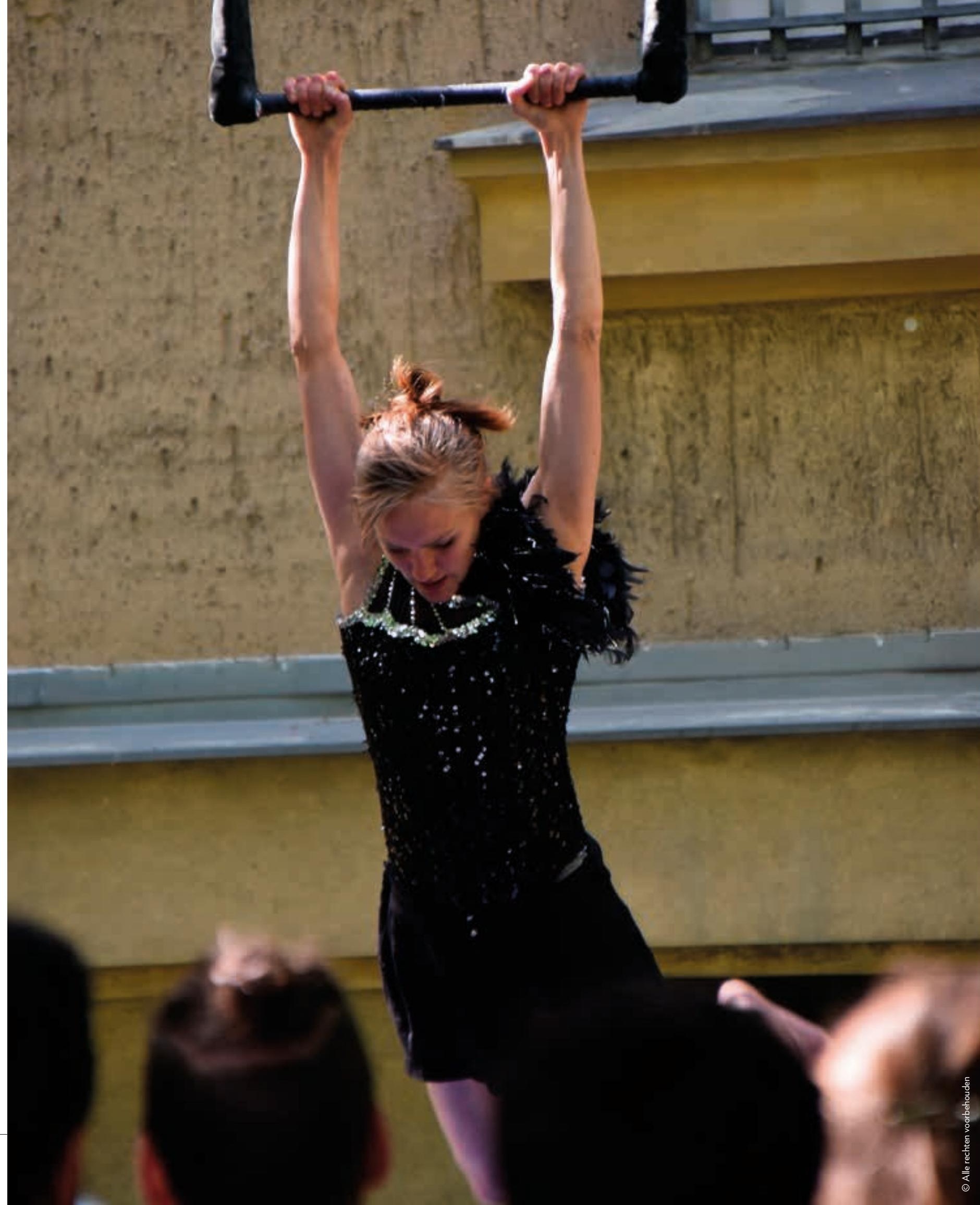

